\title{
Analisando a governabilidade presidencial a partir de padrões de homofilia na Câmara dos Deputados: Estudos de Casos no Brasil e nos EUA
}

\author{
Breno de Sousa Matos ${ }^{1}$, Carlos H. G. Ferreira ${ }^{1}$, Jussara M. Almeida ${ }^{1}$ \\ ${ }^{1}$ Departamento de Ciência da Computação - Universidade Federal de Minas Gerais \\ \{brenomatos, chgferreira, jussara\}edcc.ufmg.br
}

\begin{abstract}
In this work, we propose an approach to analyze the governability of the president based on roll call votes in the House of Representatives. In order to identify patterns of homophily between the government group and the remaining deputies, we model the roll call votes as a graph to observe how the homophily process impacts on the governability of the president in two countries, i.e., Brazil and United States.
\end{abstract}

Resumo. Neste trabalho, propomos uma abordagem para analisar a governabilidade do presidente com base nas votações realizadas na Câmara dos Deputados. Para isso, modelamos as votações em forma de um grafo, de modo a identificar padrões de homofilia entre a base do governo e os demais deputados em dois países, isto é, Brasil e Estados Unidos.

\section{Introdução}

Nos últimos anos, vários países têm vivenciado episódios polêmicos na política. No Brasil é possível citar o impeachment da ex-presidente Dilma Rousseff, marcado por uma intensa disputa entre os poderes legislativo e executivo [Fearnside 2016]. Já nos Estados Unidos (EUA), mesmo tendo a maioria das cadeiras ocupadas por deputados do seu partido, ao assumir a presidência em 2017, o presidente Donald Trump apresentou em seus primeiros meses de governo uma profunda dificuldade em manter um bom relacionamento com a Câmara dos Deputados [Washington-Post 2017].

A governabilidade constitui uma importante característica que diz respeito à capacidade de um presidente da república de governar e aplicar as políticas públicas desejadas [Santos 1997]. Porém, em países como o Brasil, isso não é tão simples, devido aos problemas no sistema político, tais como, a alta fragmentação partidária, presente em pelo menos outros 57 países [Wehner 2010], e a permutação de deputados nos partidos durante o governo [Figueiredo 2007]. Contudo, é comum que os presidentes tentem manter o maior número possível de partidos e deputados na base governista para, consequentemente, aumentar a sua governabilidade [Figueiredo 2007]. Já nos Estados Unidos, a existência de uma Câmara dos Deputados dividida entre dois partidos com ideologias cada vez mais extremas, desafia o equilíbrio entre a base governista e oposição [Andris et al. 2015].

As relações entre a base aliada do governo e os demais deputados durante as votações podem ser analisadas por meio da homofilia. A homofilia, também conhecida como assortatividade, é a tendência dos nós presentes em uma rede se conectarem a outros indivíduos similares segundo algum critério [Newman 2003]. Assim, quanto mais a alta 
a assortatividade em uma votação na Câmara dos Deputados, menor é a interação entre a base governista do presidente e os demais deputados, o que pode impor dificuldades ao governo do presidente em aprovar as votações de seu interesse. Neste contexto, nós propomos uma abordagem para analisar a governabilidade política do presidente baseada na homofilia em redes de votações na Câmara dos Deputados. Mais especificamente, estamos interessados em verificar como as relações entre os deputados da base aliada e os demais deputados estão associadas à estabilidade política do presidente em exercício. Para isso, avaliamos as votações do plenário da Câmara dos Deputados do Brasil, considerando as coalizões realizadas pelo governo nesse período. De maneira semelhante, nós aplicamos a nossa abordagem nos Estados Unidos.

\section{Materiais e Métodos}

\subsection{Trabalhos Relacionados}

A homofilia no contexto político tem sido amplamente estudada em redes sociais [Vergeer 2015]. No Twitter, usuários foram avaliados na eleição americana de 2016 em [Colleoni et al. 2014]. Já em [Halberstam and Knight 2016], são investigadas comunicações políticas em redes sociais caracterizadas por homofilia e tamanho de grupos ideológicos. Durante a votação do impeachment da ex-presidente brasileira Dilma Rousseff, um estudo revela que mensagens de um grupo raramente chegam ao grupo de ideias contrárias, caracterizando o processo de homofilia [de França et al. 2018]. Um método foi proposto em [Barber 2014] para estimar a ideologia dos usuários de mídias sociais. Em paralelo, um estudo realizado em [Vaz de Melo 2015] mostra que os partidos políticos brasileiros são altamente redundantes. Assim, o número de partidos que o país deveria ter é muito menor do que o existente. Diferentemente dos trabalhos analisados na literatura, este trabalho busca investigar o processo de homofilia no contexto político, propondo uma nova abordagem aplicada às votações na Câmara dos Deputados.

\subsection{Bases de Dados}

Os dados das votações nominais do plenário da Câmara dos Deputados do Brasil são disponibilizados através de uma interface de programação de aplicações (API) ${ }^{1}$. Foram coletadas as votações realizadas entre a $53^{\mathrm{a}}$ e a $55^{\mathrm{a}}$ legislatura, que compreende o período de 2007 a 2017. Já nos Estados Unidos, os dados das votações foram coletados pela API ProPublica ${ }^{2}$. O período considerado foi de 2009 a 2017, período compreendido entre o $111^{\circ}$ e o $115^{\circ}$ congresso. Nós também utilizamos a base de dados do Centro Brasileiro de Análise e Planejamento (CEBRAP), que fornece entre as várias informações, início, fim e partidos das coalizões realizadas pelo governo [CEBRAP 2017]. A Tabela 1 sumariza os dados das votações finais utilizadas no Brasil e Estados Unidos.

\subsection{Modelagem das Votações em Grafo}

No Brasil, um voto pode ser do tipo: Sim, Não, Abstenção ou Obstrução. De maneira similar, nos Estados Unidos um voto pode ser do tipo Yes, No e Not Voting. No Brasil,

\footnotetext{
${ }^{1}$ http: / / www2 . camara.leg.br/transparencia/dados-abertos / dados-abertos-legislativo

${ }^{2}$ https://projects.propublica.org/api-docs/congress-api/
} 
Tabela 1. Dados das Votações na Câmara dos Deputados

\begin{tabular}{|c|c|c|c|c|c|c|c|}
\hline \multicolumn{8}{|c|}{ Brasil } \\
\hline Legislatura & Ano & Presidente & Partido & \# de Votações & \# de Votos & \# de Partidos & \# de Deputados \\
\hline $53^{\mathrm{a}}$ & 2007 & Lula & PT & 209 & 76649 & 21 & 532 \\
\hline $53^{\mathrm{a}}$ & 2008 & Lula & PT & 142 & 48667 & 20 & 542 \\
\hline $53^{\mathrm{a}}$ & 2009 & Lula & PT & 148 & 50163 & 19 & 541 \\
\hline $53^{\mathrm{a}}$ & 2010 & Lula & PT & 75 & 24700 & 19 & 544 \\
\hline $54^{\mathrm{a}}$ & 2011 & Dilma & PT & 93 & 33809 & 23 & 552 \\
\hline $54^{\mathrm{a}}$ & 2012 & Dilma & PT & 73 & 24883 & 23 & 554 \\
\hline $54^{a}$ & 2013 & Dilma & PT & 137 & 47180 & 23 & 542 \\
\hline $54^{\mathrm{a}}$ & 2014 & Dilma & PT & 81 & 27686 & 24 & 556 \\
\hline $55^{\mathrm{a}}$ & 2015 & Dilma & PT & 224 & 111897 & 25 & 550 \\
\hline $55^{\mathrm{a}}$ & 2016 & Dilma/Temer & PT/PMDB & 163 & 78521 & 27 & 562 \\
\hline $55^{*}$ & 2017 & Temer & PMDB & 170 & 79473 & 26 & 534 \\
\hline \multicolumn{8}{|c|}{ Estados Unidos } \\
\hline Congresso & Ano & Presidente & Partido & \# de Votações & \# de Votos & \# de Partidos & \# de Deputados \\
\hline $111^{\circ}$ & 2009 & Barack Obama & $\mathrm{D}$ & 991 & 403549 & 3 & 442 \\
\hline $111^{\circ}$ & 2010 & Barack Obama & $\mathrm{D}$ & 664 & 273088 & 3 & 446 \\
\hline $112^{\circ}$ & 2011 & Barack Obama & $\mathrm{D}$ & 948 & 393321 & 2 & 439 \\
\hline $112^{\circ}$ & 2012 & Barack Obama & $\bar{D}$ & 658 & 270137 & 2 & 440 \\
\hline $113^{\circ}$ & 2013 & Barack Obama & $\mathrm{D}$ & 641 & 257367 & 2 & 438 \\
\hline $113^{\circ}$ & 2014 & Barack Obama & $\mathrm{D}$ & 563 & 229596 & 2 & 438 \\
\hline $114^{\circ}$ & 2015 & Barack Obama & D & 704 & 286938 & 2 & 437 \\
\hline $114^{\circ}$ & 2016 & Barack Obama & $\mathrm{D}$ & 621 & 255086 & 2 & 438 \\
\hline $115^{\circ}$ & 2017 & Donald Trump & $\mathrm{R}$ & 710 & 226712 & 2 & 441 \\
\hline
\end{tabular}

apenas os votos Sim, Não ou Obstrução foram considerados para construção dos grafos. Já nos Estados Unidos, somente os votos Yes e No foram utilizados. Então, modelamos as votações de cada país (Brasil e EUA) em grafos da seguinte forma: Para cada votação $v$ analisada, foi criado um grafo $G^{v}(V, A)$ não direcionado e não ponderado onde $V=\left\{v_{1}, v_{2}, \ldots v_{n}\right\}$ é um conjunto de vértices que representam os deputados, e $A=\left\{a_{1}, a_{2}, a_{3}, \ldots, a_{n}\right\}$ um conjunto de arestas. Uma aresta $\left(v_{i}, v_{j}\right)$ liga dois vértices (deputados) $v_{i}$ e $v_{j}(i \neq j)$, se, na votação sendo modelada, os dois deputados votaram igualmente. Por fim, cada deputado foi associado a um atributo que especifica o seu grupo, utilizado para o cálculo da assortatividade. No Brasil, os deputados foram divididos no grupo da coalizão do governo, composto por deputados de partidos que estavam na coalizão estabelecida no período da votação, e um segundo grupo composto pelos deputados cujo partido não pertencia à coalizão. Já nos Estados Unidos, foram mantidos os partidos originais.

\subsection{Métricas Avaliadas}

Após a modelagem dos grafos, foram calculadas as seguintes métricas: Assortatividade: mensura, através de um coeficiente entre -1 e 1, a preferência de nós de uma mesma rede se conectarem entre si com base em características similares [Newman 2003]; Número de vitórias e derrotas para o partido do presidente: para cada votação, verificou-se se o posicionamento da maioria do partido do presidente foi condizente com o posicionamento que venceu a votação; Número de vitórias e derrotas para a coalizão: para cada votação, foi verificada a lista de partidos que faziam parte da coalizão na data da votação, de acordo com a base de dados do CEBRAP, verificando se a coalizão venceu a votação; Tamanho da maior componente: para cada votação, verificou-se o número de deputados na maior componente do grafo.

\section{Resultados}

Iniciamos nossa análise pelo Brasil, onde a Tabela 2 mostra, por legislatura, ano e presidente, o número de derrotas e vitórias (como explicado na subseção 2.4) nas votações analisadas, em relação ao partido do presidente e a coalizão estabelecida. Por último, é apresentado o percentual médio do tamanho da maior componente para as vitórias e 


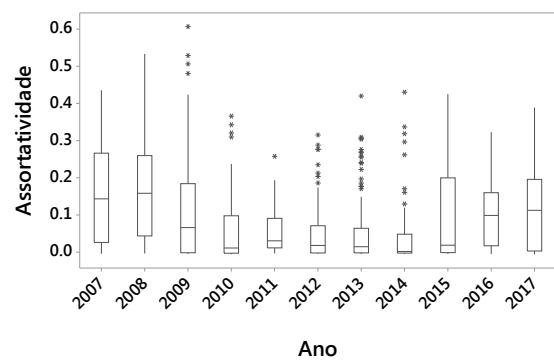

(a) Brasil

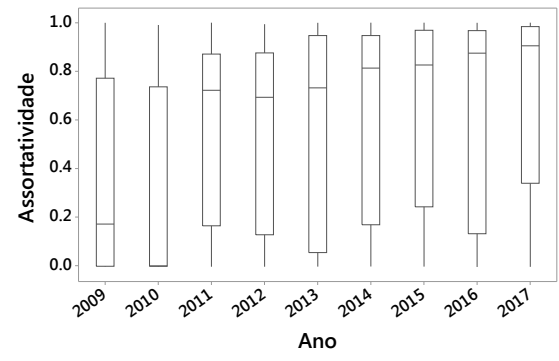

(b) Estados Unidos

Figura 1. Assortatividade calculada nas votações.

Tabela 2. Descrição das vitórias e derrotas observadas nas votações do Brasil

\begin{tabular}{|c|c|c|c|c|c|c|c|c|}
\hline \multirow{2}{*}{ Legislatura } & \multirow{2}{*}{ Ano } & \multirow{2}{*}{ Presidente } & \multicolumn{2}{|c|}{ Partido do Presidente } & \multicolumn{2}{c|}{ Coalizão do Presidente } & \multicolumn{2}{c|}{ \% Média da Maior Componente } \\
\cline { 4 - 9 } & & & \# de vitórias & \# de derrotas & \# de vitórias & \# de derrotas & Vitórias & \multicolumn{2}{c|}{ Derrotas } \\
\hline $53^{\text {a }}$ & 2007 & Lula & 198 & 11 & 202 & 7 & $80,77 \pm 1,25$ & $55,86 \pm 2,63$ \\
\hline $53^{\mathrm{a}}$ & 2008 & Lula & 140 & 2 & 141 & 1 & $82,47 \pm 1,72$ & $61,89 \pm 67,21$ \\
\hline $53^{\mathrm{a}}$ & 2009 & Lula & 137 & 11 & 142 & 6 & $82,56 \pm 1,92$ & $65,8 \pm 6,8$ \\
\hline $53^{\mathrm{a}}$ & 2010 & Lula & 70 & 5 & 73 & 2 & $85,82 \pm 3$ & $71,56 \pm 16,08$ \\
\hline $54^{\mathrm{a}}$ & 2011 & Dilma & 90 & 3 & 91 & 2 & $82,86 \pm 1,89$ & $64,8 \pm 36,59$ \\
\hline $54^{\mathrm{a}}$ & 2012 & Dilma & 63 & 10 & 67 & 6 & $83,3 \pm 3,55$ & $60,4 \pm 4,89$ \\
\hline $54^{\mathrm{a}}$ & 2013 & Dilma & 115 & 22 & 126 & 11 & $80,89 \pm 2,48$ & $62,2 \pm 4,91$ \\
\hline $54^{\mathrm{a}}$ & 2014 & Dilma & 62 & 19 & 78 & 3 & $88,44 \pm 3,47$ & $68,52 \pm 4,05$ \\
\hline $55^{\mathrm{a}}$ & 2015 & Dilma & 163 & 61 & 208 & 16 & $74,21 \pm 2,38$ & $63,58 \pm 2,03$ \\
\hline $55^{\mathrm{a}}$ & 2016 & Dilma/Temer & 72 & 91 & 155 & 8 & $80,24 \pm 2,72$ & $74,02 \pm 1,36$ \\
\hline $55^{\mathrm{a}}$ & 2017 & Temer & 92 & 78 & 165 & 5 & $81,29 \pm 3,02$ & $67,77 \pm 1,61$ \\
\hline
\end{tabular}

derrotas considerando o posicionamento do partido do presidente em exercício, com um intervalo de confiança de $95 \%$.

$\mathrm{Na} 53^{\mathrm{a}}$ legislatura, a dispersão dos valores de assortatividade calculados é relativamente alta nos dois primeiros anos do período citado (Figura 1a) quando comparados aos dois últimos da mesma Legislatura. Com assortatividade maior, há menor interação e concordância entre a oposição e os deputados da coalizão do governo. Consequentemente, isso resulta em número de derrotas superior a todos os valores registrados até o ano avaliado. No último ano de governo, é possível observar uma menor dispersão das assortatividades calculadas, além das maiores médias de deputados na maior componente, em derrotas e vitórias, considerando todos os anos de governo do ex-presidente Lula, indicando uma maior estabilidade. $\mathrm{Na} 54^{\mathrm{a}}$ Legislatura, é possível observar menor dispersão nos valores de assortatividade calculados durante os três primeiros anos (em relação à $53^{\text {a }}$ legislatura). Além disso, há um crescimento no número de derrotas proporcional nas votações, para o partido do presidente e para a coalizão. A presença de mais valores extremos e uma maior variação no percentual médio do tamanho da maior componente, para vitórias e para derrotas, indicam o início de um período de maior instabilidade, considerando todos os anos analisados até o momento.

Por último é analisada a $55^{\mathrm{a}}$ Legislatura, período governado parcialmente por Dilma (até seu impeachment em 2016) e Michel Temer. Em 2015, há enfraquecimento do governo, com maior frequência de maiores valores das assortatividades calculadas, indicando aumento no processo de homofilia, quando comparados aos demais anos sob governo da ex-presidente Dilma. A alta assortatividade associada ao crescente número de derrotas, tanto do partido do presidente quanto da coalizão estabelecida, como mostra a Tabela 2, definem um período crítico para o governo. Também em 2016, o partido do pre- 
Tabela 3. Descrição das vitórias e derrotas observadas nas votações dos EUA

\begin{tabular}{|c|c|c|c|c|c|c|}
\hline \multirow{2}{*}{ Congresso } & \multirow{2}{*}{ Ano } & \multirow{2}{*}{ Presidente } & \multicolumn{2}{|c|}{ Partido do Presidente } & \multicolumn{2}{c|}{ Média da Maior Componente } \\
\cline { 4 - 7 } & & & \# de vitórias & \# de derrotas & \# de vitórias & \# de derrotas \\
\hline $111^{\circ}$ & 2009 & Obama & 907 & 22 & $75,38 \pm 1,16$ & $58,37 \pm 2,36$ \\
\hline $111^{\circ}$ & 2010 & Obama & 622 & 9 & $77,46 \pm 0,53$ & $57,36 \pm 4,89$ \\
\hline $112^{\circ}$ & 2011 & Obama & 275 & 633 & $75,98 \pm 1,79$ & $56,71 \pm 0,32$ \\
\hline $112^{\circ}$ & 2012 & Obama & 210 & 415 & $77,48 \pm 2,14$ & $56,43 \pm 0,41$ \\
\hline $113^{\circ}$ & 2013 & Obama & 205 & 389 & $80,86 \pm 2,13$ & $54,67 \pm 0,43$ \\
\hline $113^{\circ}$ & 2014 & Obama & 179 & 352 & $78,29 \pm 2,27$ & $53,61 \pm 0,37$ \\
\hline $114^{\circ}$ & 2015 & Obama & 209 & 453 & $79,32 \pm 2,11$ & $56,29 \pm 0,33$ \\
\hline $114^{\circ}$ & 2016 & Obama & 176 & 412 & $82,66 \pm 2,29$ & $55,26 \pm 0,32$ \\
\hline $115^{\circ}$ & 2017 & Trump & 155 & 370 & $80,17 \pm 2,81$ & $53,91 \pm 0,27$ \\
\hline
\end{tabular}

sidente tem maior número de derrotas do que vitórias, um comportamento atípico em todo o período analisado. Em 2017, inteiramente sob o governo do presidente Michel Temer, o fato de que $75 \%$ das assortatividades observadas nas votações de 2017 serem menores ou iguais a 0,2 e o alto número de vitórias da coalizão, indicam uma alta governabilidade por parte do presidente. Apesar disso, o maior número de derrotas em relação ao número de vitórias, considerando o partido do presidente, indica uma instabilidade dentro do próprio partido, como mostra a Tabela 2.

Já nos Estados Unidos, o boxplot da Figura 1b apresenta a distribuição dos valores das assortatividades calculados nas votações. A Tabela 3 mostra, por congresso, ano e presidente, o número de derrotas e vitórias (Como explicado na subseção 2.4) nas votações analisadas (em relação ao partido do presidente). Por último, é apresentado o percentual médio do tamanho da maior componente para as vitórias e derrotas, considerando o posicionamento do partido do presidente em exercício, com um intervalo de confiança de $95 \%$. Durante o primeiro governo do ex-presidente Barack Obama, $111^{\circ} \mathrm{e}$ $112^{\circ}$ congresso, é possível observar na Figura $1 \mathrm{~b}$ que aproximadamente $50 \%$ das votações têm assortatividade menor ou igual a 0,2 em 2009 e 0 em 2010, respectivamente. Dessa forma, é possível identificar um governo estável, em que o processo de homofilia é menos intenso, alinhado à maior razão de vitórias sob derrotas nos anos avaliados, apresentada na Tabela 3. No $112^{\circ}$, há crescimento na porcentagem de votações com assortatividade com valores em torno de 0,7 , denotando governo mais instável em relação ao congresso anterior, também evidenciando crescente processo de homofilia. Além disso, o número de derrotas obtidas pelo partido do presidente passa a ser maior que o número de vitórias.

A instabilidade observada no fim do primeiro governo do ex-presidente Barack Obama estendeu-se para o seu segundo mandato ( $113^{\circ}$ e $114^{\circ}$ congresso). Neste período, $50 \%$ das votações possuem uma assortatividade maior que 0,8 . Além disso, o número de derrotas é sempre superior ao número de vitórias. Isto descreve o processo de homofilia em função da baixa interação entre o partido do presidente e a oposição. Entretanto, maiores valores do percentual médio do tamanho da maior componente mostram que, em alguns anos, o ex-presidente Barack Obama teve mais vitórias com uma maior margem de votos e, por outro lado, derrotas com uma menor margem de votos. No $115^{\circ}$ congresso, com o presidente Donald Trump, é possível observar frequência maior de votações com alta assortatividade, sem precedentes no período avaliado, em que $50 \%$ das votações têm assortatividade maior ou igual 0,89. Apesar da mudança de governo e partido ocorrida, a razão entre vitórias e derrotas do partido do presidente assemelha-se ao último ano de governo do ex-presidente Barack Obama. Isso também resulta no pior primeiro ano de governo para um presidente no período analisado, com uma Câmara dos Deputados cada vez mais heterogênea, indicando aumento no processo de homofilia. 


\section{Conclusão}

Este trabalho propôs avaliar o comportamento dos deputados na Câmara dos Deputados de modo a inferir padrões sob governabilidade do presidente. No Brasil, foi possível ver como os valores da assortatividade podem ser relacionados à estabilidade política do governo, observando também o número de derrotas e vitórias. Já nos Estados Unidos, em que os partidos políticos são ideologicamente polarizados, foi possível observar que o extremismo ideológico tem aumentado nos últimos anos.

\section{Referências}

Andris, C., Lee, D., Hamilton, M. J., Martino, M., Gunning, C. E., and Selden, J. A. (2015). The rise of partisanship and super-cooperators in the u.s. house of representatives. PLOS ONE, 10(4):1-14.

Barber, P. (2014). How social media reduces mass political polarization. Evidence from Germany, Spain, and the US, New York University.

CEBRAP (2017). Centro brasileiro de pesquisa e planejamento. http: / / cebrap. org.br/.

Colleoni, E., Rozza, A., and Arvidsson, A. (2014). Echo chamber or public sphere? predicting political orientation and measuring political homophily in twitter using big data. Journal of Communication, 64(2):317-332.

de França, F. O., Goya, D., and Penteado, C. C. (2018). Analysis of the twitter interactions during the impeachment of brazilian president. In Proceedings of the 51st Hawaii International Conference on System Sciences.

Fearnside, P. M. (2016). Brazilian politics threaten environmental policies. Science, 353(6301):746-748.

Figueiredo, A. C. (2007). Government coalitions in brazilian democracy. Brazilian Political Science Review, 1(2):182-216.

Halberstam, Y. and Knight, B. (2016). Homophily, group size, and the diffusion of political information in social networks: Evidence from twitter. Journal of Public Economics, 143:73-88.

Newman, M. E. (2003). Mixing patterns in networks. Physical Review E, 67(2):026126.

Santos, M. H. d. C. (1997). Governabilidade, Governança e Democracia: Criação de Capacidade Governativa e Relações Executivo-Legislativo no Brasil Pós-Constituinte. Dados, 40.

Vaz de Melo, P. O. S. (2015). How many political parties should brazil have? a datadriven method to assess and reduce fragmentation in multi-party political systems. PLOS ONE, 10(10):1-24.

Vergeer, M. (2015). Twitter and political campaigning. Sociology Compass, 9.

Washington-Post (2017). 6 months of president trump, in 7 issues. https: //www.washingtonpost.com/news/the-fix/wp/2017/07/20/ 6-months-of-president-trump-in-7-issues.

Wehner, J. (2010). Institutional constraints on profligate politicians: The conditional effect of partisan fragmentation on budget deficits. Comparative Political Studies. 